\title{
Desempenho de bezerros filhos de vacas F1 Holandês Zebu submetidas a diferentes sistemas de alimentação e manejo*
}

\section{Performance of calves from F1 Holstein x Zebu cows under different feeding systems}

\author{
José Reinaldo Mendes Ruas, ${ }^{* *}$ José Joaquim Ferreira, ${ }^{* *}$ Edilane Aparecida Silva, ${ }^{* * *}$ Arismar de Castro Menezes, ${ }^{* * *}$ \\ Felipe Zandonadi Brandão, ${ }^{* * * *}$ Marcelo Diniz Santos, ${ }^{* * * *}$ Bruno Campos de Carvalho***
}

\begin{abstract}
Resumo
A viabilização de modelo de produção no qual o bezerro é componente econômico torna-se muito relevante para todo o setor produtivo. Assim, este trabalho teve como objetivo avaliar o desenvolvimento de bezerros 3/4 Zebu Holandês filhos de vacas F1 Holandês Zebu, submetidas a diferentes períodos de ordenha e alimentadas com diferentes volumosos. As 30 vacas F1 Holandês Zebu, mães dos bezerros, foram distribuídas aleatoriamente em três tratamentos: T1 - Pastagens, mais 1,250kg de proteinado por dia e ordenhadas até o final da lactação; T2 - pastagens, mais 1,250kg de proteinado por dia e ordenhadas até o 200 dia de lactação; T3 - volumoso em cocho e ordenhadas até o final da lactação. Os bezerros foram criados em piquetes, e sua alimentação constituída de leite até 90 dias de idade e como volumoso silagem de milho na época seca e pastagens no verão. Os bezerros do T2, após o 200 de lactação, permaneceram com suas mães. Nos primeiros 200 dias de lactação, período em que todas as vacas foram ordenhadas, não houve efeito significativo dos tratamentos $(P>0,05)$ sobre os ganhos médios de peso dos bezerros. Bezerros do grupo T2, mantidos a pasto com as respectivas mães, a partir do $200^{\circ}$ dia de lactação até a secagem definitiva das vacas, apresentaram maior ganho de peso. O manejo alternativo de ordenhar vacas até o 200 dia de lactação e posteriormente mantê-las com os bezerros até a secagem definitiva, sem que sejam ordenhadas, promove maior ganho de peso dos bezerros em relação ao manejo tradicional.
\end{abstract}

Palavras-chave: criação de bezerros, ganho de peso, manejo de ordenha, proteinado, vacas F1.

\begin{abstract}
The viability of production system in which the calf is an economic component is relevant for the entire production sector. This study was carried out to evaluate the growth of $3 / 4 \mathrm{HZ}$ calves, progenies of $\mathrm{F} 1 \mathrm{HZ}$ cows submitted to three milking periods and fed different roughages. Thirty F1 cows were randomly allotted to three feeding treatments: T1 - Pasture plus $1.250 \mathrm{~kg}$ of supplement/day; T2 - Pasture plus $1.250 \mathrm{~kg}$ of supplement/day; T3 - Roughage offered in feedlot. The cows were milked daily to the end of the lactation period, except for cows of treatment T2, which were milked during 200 days of lactation. Calves were fed milk until 60 days of age and corn silage during the dry season and pastures in the rainy season. The T2 calves remained with their mothers from 200 days to the end of the lactation period. No difference $(P>0.05)$ among treatments for calf weight gain until the 200 days of lactation was observed. After 200 days of lactation, T2 calves, remaining with their no milked mothers, showed higher weight gain $(P<0.05)$ in comparison to calves of the other treatments. Calves allotted to the alternative system in which they remained with their no milked mother from 200 days of lactation to the end of lactation period show higher weight gain, in comparison to calves from the traditional system.
\end{abstract}

Keywords: calf, weight gain, milking system, supplement, F1 cows.

\section{Introdução}

No Brasil, é conhecida a predominância do gado mestiço leiteiro, oriundo de vários sistemas de cruzamento entre as raças européias especializadas e as raças zebuínas.
Atualmente, há tendência de se produzir leite, a partir de vacas mantidas em pastagens, visando à diminuição dos custos de produção, em razão, principalmente, do elevado preço do concentrado e do volumoso, oferecido em cocho, durante a estação das secas. Segundo Gomide et al. (2001), as

\footnotetext{
* Projeto financiado pela Fapemig - CAG 350/04.

** Pesquisador Epamig-DPPE- Belo Horizonte. e-mail: jrmruas@epamig.br.

*** Pesquisador Epamig.

**** Prodessor adjunto da Faculdade de Veterinária da Universidade Federal Fluminense.

${ }^{* * * * *}$ Professor da Universidade de Cuibá.
} 
pastagens tropicais, quando bem manejadas, são capazes de sustentar níveis satisfatórios de produção de leite e carne, sobretudo nas épocas mais favoráveis do ano.

A bovinocultura européia e a americana especializaram-se muito em produção de leite ou em produção de carne. Essa especialização ocorreu em consequência da necessidade da melhoria constante de desempenho em ambos os setores. Em decorrência, desenvolveram-se raças bastante eficientes para cada propósito, como a Holandesa para produção de leite e o Aberdeen Angus para produção de carne; outras foram desenvolvidas com o duplo propósito, como a Suíça e a Simental. Animais dessas raças ficaram, no entanto, aquém em produtividade quando comparadas com o desempenho das raças especializadas (Silva, 1992).

No Brasil também são realizados trabalhos que visam buscar um animal de duplo propósito. Nas avaliações de produção de leite, vacas adultas das raças Gir e Guzerá mostraram produção em torno de $2.700 \mathrm{~kg}$ em até 305 dias de lactação (Martinez e Teodoro, 1992; Winkler e Penna, 1992). Relativo ao desenvolvimento ponderal, animais Gir mostraram-se inferiores às demais raças zebuínas (Peixoto, 1983; Winkler e Penna, 1992). Outras tentativas redundaram na formação de raças sintéticas como a Pitangueiras e a Lavinia (Viana, 1975), ou simplesmente em cruzamentos de vacas mestiças com uma terceira raça, sempre com o objetivo de obter produtos que se prestassem à produção de carne e de leite.

Encontrar um animal que desempenhe as duas funções, produção de leite e de carne, não é tarefa simples pelas próprias características que, no geral, são antagônicas. Sem comprometer a produção de leite, o bezerro, principalmente oriundo de rebanhos mistos, precisa ser encarado como um componente potencialmente lucrativo do sistema. Para aproveitar economicamente o bezerro de origem leiteira, há necessidade de desenvolvimento de pesquisas e técnicas capazes de viabilizar sua criação. Um caminho é desenvolver pesquisas em nutrição para um bezerro já rotineiramente produzido. Outro é produzir bezerros direcionados para o corte. Nesse caso o animal deve receber manejo nutricional, associado às práticas convencionais de criação de bezerro de corte, incluindo a escolha da raça paterna, adequada à finalidade. Em se tratando de mestiços, é preciso viabilizar um modelo de produção de leite, no qual o bezerro seja um componente econômico e propósito relevante, até para tornar a atividade mais competitiva. No que se refere à composição da receita da atividade leiteira, a venda de animais tem contribuído de forma significativa levando a viabilização da atividade (Sebrae-MG/FAEMG, 1995 e Anualpec, 2002).

Os ganhos de pesos obtidos antes da desmama não precisam necessariamente ser altos, mas devem ser suficientes para garantir boa saúde e bom desenvolvimento esquelético do bezerro (Wattiaux, 1996). Entretanto, para se obter um produto com bom desenvolvimento, seja para reposição de matrizes ou para abate, é preciso maior eficiência de crescimento até a desmama. Em gado de corte, essa eficiência está sustentada essencialmente na maior ou menor integração do binômio vaca-bezerro, que é condicionado pela influência de vários fatores endógenos e exógenos, e por complexas interações fenotípicas, genotípicas e ambientais (Peixoto, 1983). Esse autor ainda destaca que o período do nascimento à desmama, constituise, em relação ao desenvolvimento, o segmento mais importante da vida do animal, pois o bezerro de corte consegue em sete meses atingir 25 a $35 \%$ de seu peso de abate, enquanto, para completar o restante de seu desenvolvimento, necessita, em média, de mais 30 a 40 meses. A habilidade materna da vaca é considerada a principal responsável pelo desempenho do bezerro até a desmama. A magnitude deste efeito é determinada especialmente pela produção de leite da vaca, responsável por $66 \%$ da variação de peso dos bezerros até a desmama.

Como o peso do bezerro a desmama está diretamente relacionado com o volume de leite disponibilizado pela mãe e sabendo-se que no início da vida o bezerro não é considerado ruminante, o efeito da quantidade de leite ingerido sobre o ganho de peso diário torna-se mais evidente (McCarter et al.,1991).

O potencial do bezerro, proveniente do rebanho leiteiro, para produção de carne, deixa de ser explorado pelos produtores de leite em razão da falta de um sistema econômico de produção, que conviva harmonicamente com a renda única da comercialização do leite. Os sistemas de produção de leite atualmente empregados não contemplam, de forma geral, o aproveitamento do bezerro, e qualquer tentativa de fazê-lo tem determinado em elevados custos de produção e falta de um mercado que remunere satisfatoriamente esse produto (Lucci, 1989, citado por Ribeiro, 1997). Em 1997, Ribeiro trabalhou com bezerros holandeses confinados e verificou a viabilidade técnica de criar esses animais, mas não conseguiu viabilidade econômica para nenhuma das dietas utilizadas, fato que levou o autor a concluir que, nesse caso, há necessidade de pesquisas que busquem soluções econômicas.

Assim, o presente trabalho teve como objetivo avaliar o efeito de diferentes manejos da lactação sobre o ganho de peso das crias; avaliar o efeito de diferentes regimes de nutrição sobre o ganho de peso das crias; e avaliar o efeito dos diferentes sistemas de manejos sobre o desempenho econômico da atividade.

\section{Material e métodos}

O experimento foi conduzido na Fazenda Experimental de Felixlândia - Epamig, localizada no município de Felixlândia, MG, situado a $18^{\circ} 7^{\prime}$ de latitude $S$ e $45^{\circ}$ de longitude W Gr. O clima de Felixlândia é do tipo Aw, segundo a classificação de Köeppen, ou seja, clima tropical de savana, caracterizado por inverno seco (estação seca) e verão chuvoso (estação chuvosa), no período de janeiro a novembro de 2005.

Foram utilizadas 30 vacas, F1 Holandês $x$ Zebu, e respectivos filhos $3 / 4$ Zebu $\times 1 / 4$ Holandês, distribuídas aleatoriamente a três tratamentos: T1 - vacas suplementadas com proteinado durante a estação seca, mantidas em pastagens diferidas de Brachiaria decumbens e ordenhadas até o final da lactação; T2 - vacas suplementadas com proteinado durante a estação seca, mantidas em pastagens diferidas de Brachiaria decumbens e ordenhadas até o 200 de lactação; T3 - vacas suplementadas com volumoso em cocho e ordenhadas até o final da lactação.

A partir do mês de junho, o proteinado contendo $33,43 \%$ de $\mathrm{PB}$ foi fornecido para as vacas dos tratamentos 1 e 2 na quantidade $1,25 \mathrm{~kg}$ por cabeça por dia. A suplementação com 
concentrado foi realizada durante a ordenha, de acordo com a produção de leite, onde para quilo de leite produzido foram ofertados $3 \mathrm{~kg}$ de concentrado, a partir dos $5 \mathrm{~kg}$ de leite produzidos. As vacas com produção maior do que $8 \mathrm{~kg}$ foram ordenhadas duas vezes por dia, às $6 \mathrm{~h}$ e às $14 \mathrm{~h}$, e aquelas com produção menor que $8 \mathrm{~kg}$, apenas uma vez por dia, em sala de ordenha mecanizada.

Para realizar as avaliações foram considerados três períodos: P1 - período em que todas as vacas foram mantidas em pastagens e ordenhadas, com duração média de 118 dias, que compreendeu do parto ao início da suplementação proteica e volumosa; P2 - com duração média de 79 dias, quando as vacas dos tratamentos $\mathrm{T} 1$ e $\mathrm{T} 2$ receberam suplementação proteica no pasto e as vacas do T3 foram suplementadas no cocho com volumoso composto de $50 \%$ de silagem de milho, $50 \%$ de cana e 250 gramas de concentrado nitromineral, nesse período todas as vacas foram ordenhadas; P3 - com duração média de 46 dias, onde as vacas dos tratamentos T1 continuaram recebendo suplementação proteica no pasto, as vacas do T2 foram soltas no pasto com suas crias e não mais recebiam suplementação proteinada e as vacas do T3 continuavam suplementadas no cocho com volumoso composto de $50 \%$ de silagem de milho, 50\% de cana e 250 gramas de concentrado nitromineral, nesse período as vacas dos tratamentos T1 e T3 foram ordenhadas. As do T2 não foram ordenhadas, somente avaliadas as produções de leite.

Os bezerros foram criados em piquetes, com sal mineralizado à vontade. Esses não receberam nenhuma ração concentrada e sua alimentação foi constituída de leite até 90 dias de idade, proveniente de uma teta quando da ordenha e mais silagem de milho como volumoso durante a estação seca. Após os 90 dias até a desmama os bezerros dos T1 e T3 continuavam recebendo volumoso e mais o leite residual, pois os mesmos tinham acesso às suas mães após a ordenha. Os bezerros do T2 recebiam o mesmo tratamento até o $200^{\circ}$ de lactação, e após esse período permaneciam com as suas mães, ficando assim disponível todo o leite e pasto e não mais recebia volumoso no cocho.

Para avaliar o ganho de peso dos bezerros, promoveu-se a pesagem de animais a cada 14 dias, que foram ajustados para os períodos avaliados. Esses dados foram submetidos à análise de variância e as médias testadas pelo teste SNK.

\section{Resultados e discussão}

Os bezerros foram criados em piquetes, com sal mineralizado à vontade. Estes não recebiam nenhuma ração concentrada e sua alimentação foi constituída de leite até 90 dias de idade, proveniente de uma teta quando da ordenha, uma vez que todos os bezerros tinham acesso a sua mãe. O consumo de leite neste período foi estimado calculando-se a produção de leite por teta, uma vez que durante o controle leiteiro foram ordenhadas apenas três tetas nos primeiros 90 dias de lactação (Tabela 1). A média do consumo por dia em todos os tratamentos foi de 3,41 litros por bezerro.

Tabela 1: Consumo estimado de leite pelos bezerros até 90 dias (CEL) durante o experimento de vacas mestiças F1 (HZ) submetidas aos diferentes tratamentos - variáveis de controle

\begin{tabular}{cccc}
\hline & & \multicolumn{2}{c}{ CEL $(\mathrm{kg})$} \\
\cline { 3 - 4 } $\mathrm{T}^{*}$ & $\mathrm{n}^{* *}$ & Média & Desvio-padrão \\
\hline $\mathrm{T} 1$ & 10 & 303,93 & 50,78 \\
$\mathrm{~T} 2$ & 10 & 304,36 & 44,76 \\
$\mathrm{~T} 3$ & 10 & 312,75 & 37,50 \\
\hline
\end{tabular}

${ }^{*}$ Refere-se aos tratamentos.

${ }^{* *}$ Refere-se ao número de animais por tratamento. $(P>0,05)$

Os pesos médios ao nascimento, ao final do primeiro período e ganho médio diário no primeiro período foram 38,9, 84,3 e $0,37 \mathrm{~kg} ; 41,4,86,6$ e 0,37kg; 39,9, 86,9 e 0,38kg para bezerros dos tratamentos 1, 2 e 3 respectivamente (Tabela 2). Não foram observadas diferenças entre os tratamentos, como esperado, visto que todos os animais foram submetidos ao mesmo manejo. O ganho médio de 370 gramas por dia é considerado reduzido; entretanto, ao se considerar o consumo médio de leite no período, que foi 3,41 litros por dia, o ganho foi satisfatório.

Tabela 2: Pesos dos bezerros filhos de vacas mestiças $F 1(H Z)$ submetidas aos diferentes tratamentos: peso ao nascimento (PN), peso ajustado para o final do período 1 (PA1), ganho de peso total (GPT1) e ganho médio diário (GMD1) durante o período 1

\begin{tabular}{cccccccccc}
\hline & & \multicolumn{2}{c}{$\mathrm{PN}(\mathrm{kg})$} & \multicolumn{2}{c}{ PA1 $(\mathrm{kg})$} & \multicolumn{2}{c}{ GPT1 $(\mathrm{kg})$} & \multicolumn{2}{c}{ GMD1 $(\mathrm{kg})$} \\
\cline { 3 - 9 } $\mathrm{T}^{*}$ & $\mathrm{n}^{* *}$ & Média & Desvio & Média & Desvio & Média & Desvio & Média & Desvio \\
\hline T1 & 10 & 38,90 & 4,53 & 84,30 & 16,73 & 45,40 & 17,75 & 0,37 & 0,12 \\
T2 & 10 & 41,40 & 7,79 & 86,59 & 13,28 & 45,19 & 12,71 & 0,37 & 0,96 \\
T3 & 10 & 39,90 & 6,49 & 86,88 & 15,92 & 46,98 & 12,50 & 0,38 & 0,57 \\
\hline
\end{tabular}

*Refere-se aos tratamentos.

${ }^{* *}$ Refere-se ao número de animais por tratamento. ( $\left.P>0,05\right)$

No período dois, quando se iniciou a suplementação da seca, as vacas foram submetidas a tratamentos diferenciados, enquanto os bezerros recebiam o mesmo manejo alimentar, assim também não foram observadas diferenças nos ganhos dos bezerros (Tabela 3).

Para o período 3, os bezerros das vacas do grupo T2 foram colocados no pasto com suas respectivas mães, as quais não recebiam mais proteinado, e os bezerros das vacas dos grupos T1 e T3 continuaram com o mesmo tratamento do período anterior, ou seja, amamentavam-se apenas do leite residual. Observou-se maior ganho de peso dos bezerros do T2 $(P<0,05)$, o que vai de encontro aos resultados obtidos por McCarter et al.(1991), e ganho de peso semelhante para bezerros dos tratamentos 1 e $3(P>0,05)$. Esses resultados indicam que o leite residual não foi suficiente para manter 0 
Tabela 3: Pesos dos bezerros filhos de vacas mestiças F1 (HZ) submetidas aos diferentes tratamentos: peso ajustado para o final do período 2 (PA2), ganho de peso total (GPT2) e ganho médio diário (GMD2) durante o período 2

\begin{tabular}{cccccccc}
\hline & & \multicolumn{2}{c}{ PA2 $(\mathrm{kg})$} & \multicolumn{2}{c}{ GPT2 $(\mathrm{kg})$} & \multicolumn{2}{c}{ GMD2 $(\mathrm{kg})$} \\
\cline { 3 - 7 } $\mathrm{T}^{*}$ & $\mathrm{n}^{* *}$ & Média & Desvio & Média & Desvio & Média & Desvio \\
\hline $\mathrm{T} 1$ & 10 & 112,46 & 14,12 & 28,16 & 9,64 & 0,35 & 0,71 \\
$\mathrm{~T} 2$ & 10 & 114,29 & 20,13 & 27,70 & 14,29 & 0,36 & 0,11 \\
$\mathrm{~T} 3$ & 10 & 112,13 & 9,86 & 25,24 & 12,75 & 0,31 & 0,93 \\
\hline
\end{tabular}

*Refere-se aos tratamentos.

${ }^{* *}$ Refere-se ao número de animais por tratamento. $(P>0,05)$

mesmo ganho de peso dos animais que ficaram junto de suas mães (Tabela 4). Mas, de acordo com Wattiaux (1996), os ganhos de pesos obtidos antes da desmama não precisam necessariamente ser altos, mas devem ser suficientes para garantirem boa saúde e bom desenvolvimento esquelético do bezerro, fato que ocorreu no presente experimento.

Tabela 4: Pesos dos bezerros filhos de vacas mestiças $F 1(H Z)$ submetidas aos diferentes tratamentos: peso ajustado para o final do período 3 (PA3), ganho de peso total (GPT3) e ganho médio diário (GMD3) durante o período 3

\begin{tabular}{cccccccc}
\hline & & \multicolumn{2}{c}{ PA3 $(\mathrm{kg})$} & \multicolumn{2}{c}{ GPT3 $(\mathrm{kg})$} & \multicolumn{2}{c}{ GMD3 $(\mathrm{kg})$} \\
\cline { 3 - 7 } $\mathrm{T}$ & $\mathrm{N}$ & Média & Desvio & Média & Desvio & Média & Desvio \\
\hline T1 & 10 & $134,87^{\mathrm{b}}$ & 11,50 & $22,41^{\mathrm{b}}$ & 7,11 & $0,71^{\mathrm{b}}$ & 0,22 \\
T2 & 10 & $163,37^{\mathrm{a}}$ & 32,98 & $49,08^{\mathrm{a}}$ & 20,20 & $1,17^{\mathrm{a}}$ & 0,33 \\
T3 & 10 & $139,04^{\mathrm{b}}$ & 18,22 & $26,91^{\mathrm{b}}$ & 10,14 & $0,53^{\mathrm{b}}$ & 0,15 \\
\hline
\end{tabular}

a,bMédias seguidas de letras diferentes, na mesma coluna, diferem $(P<0,05)$, pelo teste SNK.

* Refere-se aos tratamentos.

** Refere-se ao número de animais por tratamento.

Conforme dados apresentados na Tabela 5, observou-se que a diferença constatada no período três influiu no peso final dos bezerros do grupo T2 $(P<0,05)$, que desmamaram mais pesados. Esses achados demonstram que manejos que proporcionam melhores ganhos de peso durante a fase de amamentação, aumentarão do peso a desmama e consequentemente resultarão em melhores produtos.

Quando se pensa na venda de bezerros provenientes de rebanhos leiteiros, o principal ponto a ser considerado é a sua qualidade. Se forem destinados a rebanho de leite, no caso de fêmeas, o baixo desenvolvimento pode comprometer a produção futura de leite e a reprodução. Em caso de gado de corte, segmento em que o bezerro vale quanto pesa, bezerros com baixo peso a desmama, são desvalorizados, principalmente aqueles com comprometimento no desenvolvimento esquelético e muscular.

No caso do presente trabalho, os bezerros, que são $3 / 4$ Zebu X $1 / 4$ Holandês, foram destinados para a venda a produtores de gado de corte. No preço atual, podemos considerar que um quilo de bezerros equivale a 3,11 litros de leite. Como os bezerros foram desmamados em média com 145,87 quilos, e se multiplicarmos pelo equivalente leite, significa uma produção de 453,65 kg de leite em uma lactação, com pouco custo adicional, visto que o bezerro não recebe ração concentrada. Ao se considerar em $20 \%$ a margem de lucro em um litro de leite, este adicional equivaleria ao lucro de uma lactação de 2.268 quilos, produção esta superior à média nacional, de $1.154 \mathrm{~kg}$ por lactação. Além disso, a presença do bezerro em sistemas que utilizam vacas mestiças pode contribuir para a melhoria da qualidade do leite e saúde da glândula mamária.

\section{Conclusões}

O desenvolvimento das crias até os 200 dias de lactação não foi afetado pelo manejo alimentar imposto às mães. A permanência constante dos bezerros com as suas mães após o 200 de lactação proporcionou maior ganho de peso e com isto maior peso à desmama. Quando se desejar incrementar ganhos de peso com vistas à obtenção de um produto de melhor qualidade esta prática pode ser utilizada.
Tabela 5: Pesos dos bezerros filhos de vacas mestiças $\mathrm{F} 1(\mathrm{HZ})$ submetidas aos diferentes tratamentos: peso ajustado para o final do período de avaliação (PAT), ganho de peso total (GPT) e ganho médio diário (GMDT) durante o período total de avaliação

\begin{tabular}{cccccccc}
\hline & & \multicolumn{2}{c}{ PAT $(\mathrm{kg})$} & \multicolumn{2}{c}{ GPT $(\mathrm{kg})$} & \multicolumn{2}{c}{ GMDT $(\mathrm{kg})$} \\
\cline { 3 - 7 } $\mathrm{T}$ & $\mathrm{N}$ & Média & Desvio & Média & Desvio & Média & Desvio \\
\hline T1 & 10 & $137,66^{\mathrm{b}}$ & 11,75 & $98,76^{\mathrm{a}, \mathrm{b}}$ & 14,22 & $0,428^{\mathrm{b}}$ & 0,69 \\
$\mathrm{~T} 2$ & 10 & $160,53^{\mathrm{a}}$ & 28,64 & $119,13^{\mathrm{a}}$ & 27,70 & $0,493^{\mathrm{a}}$ & 0,98 \\
T3 & 10 & $139,43^{\mathrm{b}}$ & 17,76 & $99,54^{\mathrm{b}}$ & 14,35 & $0,398^{\mathrm{b}}$ & 0,42 \\
\hline
\end{tabular}

$a, b$ Médias seguidas de letras diferentes, na mesma coluna, diferem $(P<0,05)$, pelo teste SNK.

* Refere-se aos tratamentos.

** Refere-se ao número de animais por tratamento. 


\section{Referências}

GOMIDE, J.A., WENDLING, I.J., BRAS, S.P., QUADROS, H.B. Consumo e produção de leite de vacas mestiças em pastagem de brachiaria decumbens manejadas sob duas ofertas diárias de forragem. Revista Brasileira de Zootecnia, v. 30, n. 4, p. 1194-1199, 2001.

MARTINEZ, M.L., TEODORO, R.L. Programa nacional de melhoramento genético do gir leiteiro. Informe Agropecuário, v. 16, n. 177, p. 7-9, 1992.

McCARTER, M.N., BUCHANEN, D.S., FRAHM, R.R. Comparison of crossbred cows containing various proortions of bhraman in spring or fall calving systems. II. Milk production. Journal Animal Science, v. 69, p. 77-84, 1991.

PEIXOTO, A.M. Fatores que interferem no crescimento do gado de corte até desmama. In: Simpósio sobre pecuária de corte. 3. Anais, Fundação Cargil, p. 73-109, 1983.
RIBEIRO, T.R. Desempenho e qualidade da carcaça de bezerros holandeses alimentados com dietas contendo diferentes níveis de concentrado. Viçosa, Universidade Federal de Viçosa, 89 p. Tese (Mestrado em Zootecenia), 1997.

SILVA, H.M. Raças leiteiras européias para os trópicos. Informe Agropecuário, v. 16, n. 177, p. 5-7, 1992.

VIANA, J.A.C. Visão panorâmica das necessidades de pesquisa. Seminário de Gado de Leite - EPAMIG, EMBRAPA, ESAL, UFMG, UFV, Juiz de Fora, p. 62-73, 1975.

WATTIAUX, M.A. Feeding calves and heifers, In: RAISING DAIRY HEIFERS, Technical Dairy Guide, Universty of Wisconsin, Madson, p. 31-49, 1996.

WINKLER, R., PENNA, V.M. O guzerá. Informe Agropecuário, v. 16, n. 177, p. 10-14, 1992. 